\title{
Involuntary Movements with Cerebellar Tumour
}

\author{
P.B. Jayakar and S.S. Seshia
}

\begin{abstract}
We describe a child with a cerebellar astrocytoma who presented with paroxysmal segmental rhythmic myoclonus. The movement disorder was characterized by focal onset in the left eyelid followed by a sequential march of clinical events. There were no clinical or laboratory findings to suggest brainstem infiltration or cerebral involvement. Marked clinical improvement followed tumour resection. We suggest that the cerebellar lesion was primarily responsible for the movement disorder.
\end{abstract}

RÉSUMÉ: Mouvements involontaires associés à une tumeur cérébelleuse. Nous décrivons le cas d'un enfant porteur d'un astrocytome cérébelleux qui s'est présenté avec un tableau de myoclonies rythmiques segmentaires paroxistiques. L'anomalie du mouvement était caractérisée par un début focal au niveau de la paupière de l'oeil gauche suivi par une cascade d'événements cliniques. Il n'y avait aucune manifestation clinique ou de laboratoire suggestive d'une infiltration du tronc ou des hémisphères cérébraux. A la suite de la résection de la tumeur, l'état clinique s'est amélioré considérablement. Nous croyons que la lésion cérébelleuse était essentiellement responsable du désordre du mouvement.

Can. J. Neurol. Sci. 1987; 14:306-308

Involuntary facial movements can result from lesions of the cerebral cortex, basal ganglia, brainstem, cerebellar connections, facial nucleus or facial nerve.

We describe a one year old child with frequent focal involuntary facial movements. He had a cerebellar astrocytoma, a lesion hitherto not associated with such phenomena.

\section{Case Report}

This boy was normal until one year of age when he developed paroxysmal involuntary movements of the face. Each episode started with tonic and clonic contractions of the left eyelid. The right eyelid and the left angle of the mouth were involved within seconds. Frequently there would then be deviation of the eyes upward and to the right, chewing, mouthing and respiratory movements. Deviation of the head to the right side occurred in some episodes and involuntary movements of the left arm were also seen on two occasions. The episodes waxed and waned. The movements were rhythmic and occurred at a frequency of 1 to 3 per second. They lasted from 3 seconds to 30 minutes and recurred frequently at intervals of less than 15 minutes during the awake state. Consciousness was not perceptibly affected and the palate was never involved. Episodes were rare during sleep and were not precipitated by stimuli. A part from the movements, the only neurological findings at the age of 13 months were mild inco-ordination and impaired parachute reflex in the left upper limb. Ocular movements were normal between episodes. There was no evidence of a neurocutaneous disorder in the child or in his parents.
Several polygraphic electroencephalograms were done over the next 3 months. The records confirmed the sequential march of clinical events (Figure 1).

Computed tomographic (CT) scans of the brain, including high resolution cuts of the posterior fossa, done at the ages of 13 and 15 months were normal, as were right carotid angiogram, brainstem auditory evoked potentials and radionuclide brain scan.

Cerebrospinal fluid (CSF) examinations on three occasions between the ages of 13 months and 15 months were normal. Serial tests also done at these times on CSF and serum for viruses, mycoplasma pneumonia, toxoplasmosis and syphilis showed no evidence of infection; tests for metabolic disorders showed no abnormality.

The involuntary movements did not respond either to therapeutic levels of anticonvulsants including phenobarbitone, phenytoin, valproate, carbamazepine, clonazepam or to haloperidol, pyridoxine and biotin. Anticonvulsant drugs were used singly and in combination. Diazepam given intravenously produced no response.

A third CT scan (Figure 2) at the age of 17 months showed a $3.5 \mathrm{~cm}$ homogeneous left cerebellar mass which extended anteriorly as far as the ambient cistern and produced a slight contralateral shift of the cerebellum. The ventricular system and cerebellopontine angles were normal. A left vertebral angiogram done at this time was normal. The mass was almost totally resected at the age of 18 months and found to be a low grade dense fibrillary astrocytoma.

There was a marked improvement in the frequency and severity of involuntary movements immediately after surgery. The child has been followed up for a further $31 / 2$ years. He has not been treated with radiotherapy or chemotherapy and is not on any drugs. He no longer has any involuntary movements. Now 5 years old, he is neurologically

From the Department of Pediatrics and Child Health, University of Manitoba and Children's Hospital, Winnipeg

Presented at the XIX Canadian Congress of Neurological Sciences, Edmonton. Canada, June 1984

Received November 13, 1986. Accepted in final form March 14, 1987.

Reprint requests to: Dr. S.S. Seshia, Section of Pediatric Neurosciences, Children's Hospital, 840 Sherbrook Street, Winnipeg, Manitoba, Canada R3A IS1 


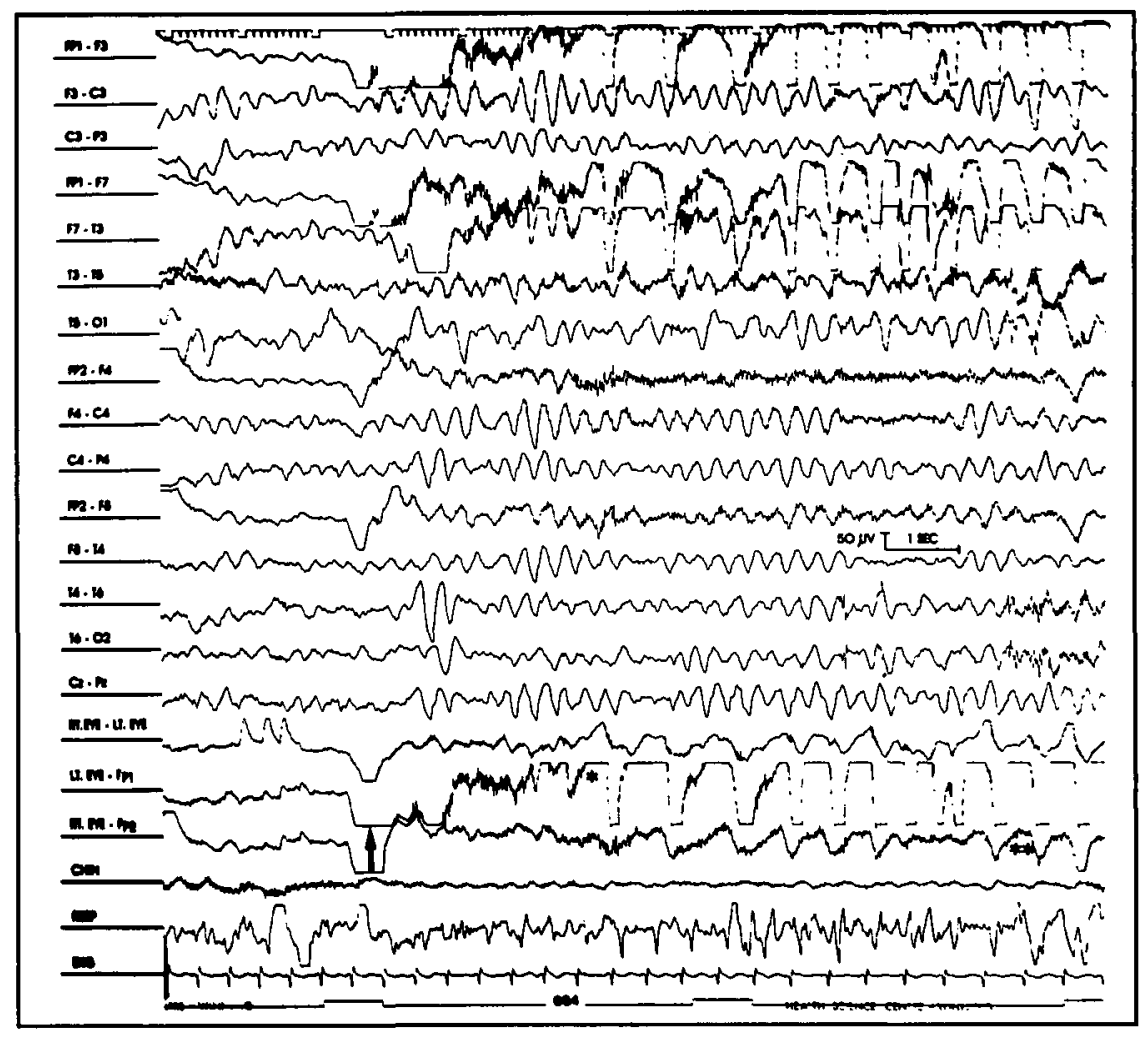

A

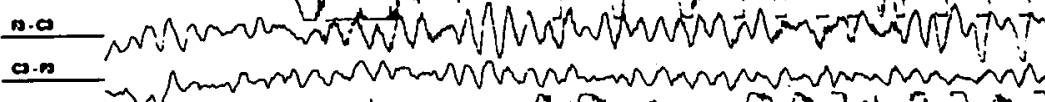
n.n n.n

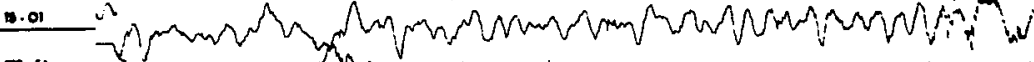
m.M

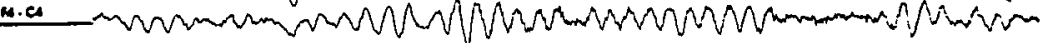

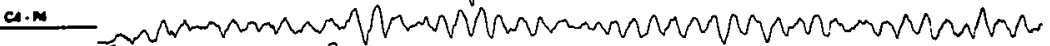

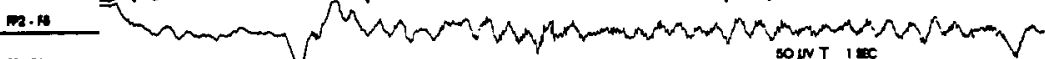
由.4

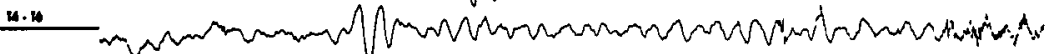

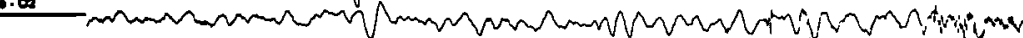

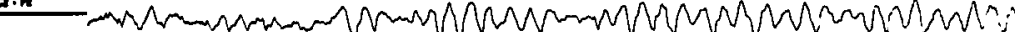
$=m_{m}^{m}$

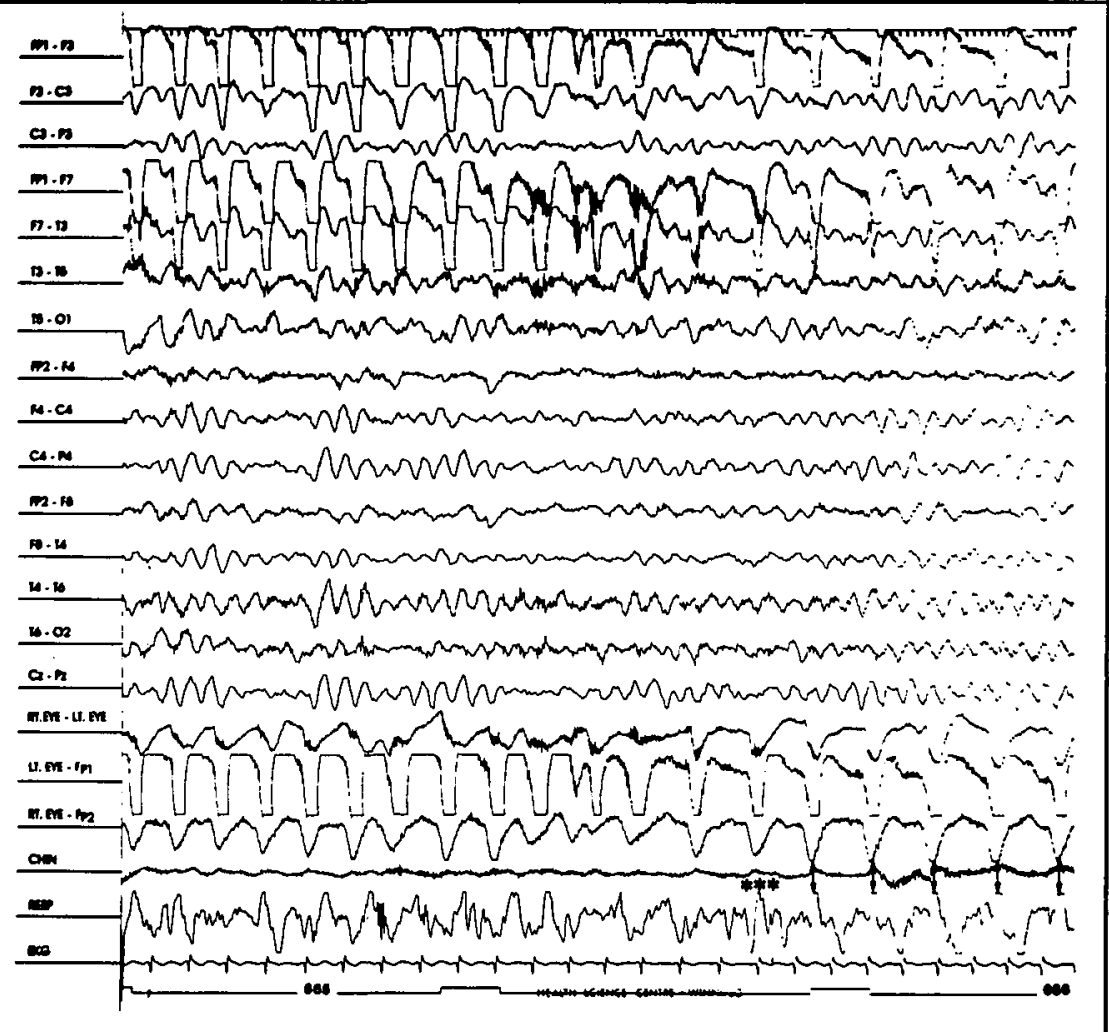

B

Figure I(A) - Polygraphic EEG showing the march of clinical events. Onset of episode (arrow) with tonic contraction of the left eyelid, followed by tonic clonic movements of the left eyelid $\left(^{*}\right)$ and then by involvement of right eyelid $\left(^{* *}\right)$. Note corresponding artifact in $F p_{1}-F_{3}, F p_{1}-F_{7}$ and $F_{7}-T_{3}$. (B) Continuation of EEG (same clinical event) showing onset of involuntary respiratory movements (***) in synchrony with those of the eyelids ( ). 
normal except for mild inco-ordination in the left upper limb. He is normal on the Yale development schedule but for a slight delay in linguistic skills. CT scans done at 6 month intervals post-operatively, show neither local progression of the mass nor supratentorial involvement. Brainstem auditory evoked potentials. short latency somatosensory evoked potentials and orbicularis oculi reflex studies have been normal for age on serial testing.

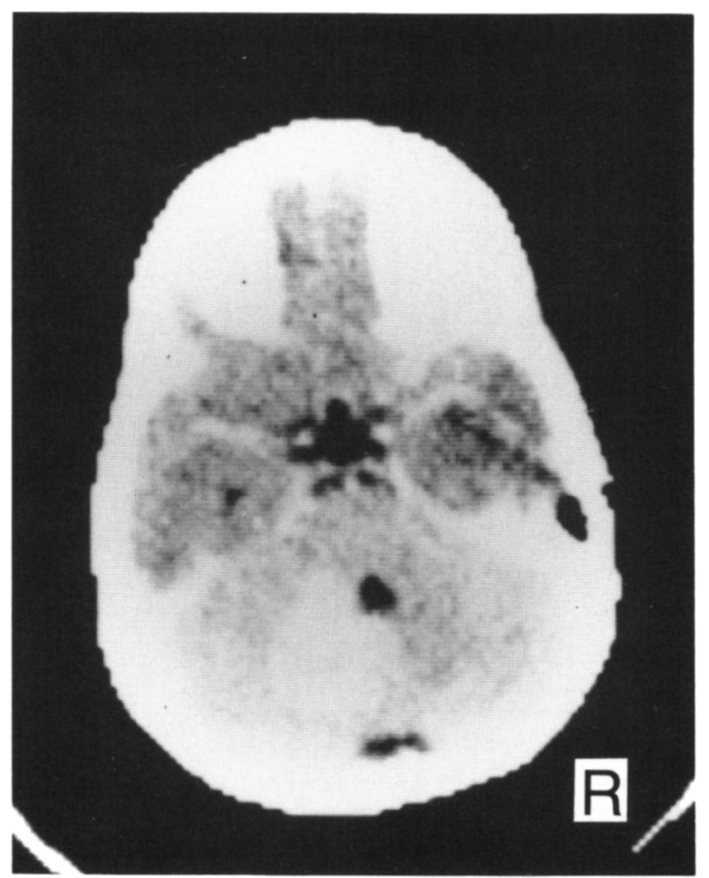

Figure $2-C . T$. scan showing a homogeneous left cerebellar mass. The ventricular system and cerebellopontine angle are normal.

\section{Discussion}

Children with cerebellar astrocytomas usually present with features of raised intracranial pressure and cerebellar incoordination. In our case, involuntary facial movements were the initial and most prominent symptom.

Clinically, these movements can be best described as paroxysmal segmental rhythmic myoclonus and have to be differentiated from hemifacial spasms, myokymia, focal dystonia, focal facial spasms, tics and epileptic seizures.

The tonic or clonic facial movements in hemifacial spasms are rarely bilateral. ${ }^{\prime}$ They are usually due to compression of the extraaxial portion of the facial nerve. The bilateral eyelid involvement in our child as well as the ocular deviation, chewing and respiratory movements are features against the diagnosis of hemifacial spasms. Furthermore, the cerebellopontine angles and the fourth ventricle were normal on CT scans.

Facial myokymia characterized by fine continuous undulating movements, ${ }^{2}$ blepharospasm, a type of focal dystonia ${ }^{3}$ and the intermittent, irregular contractions seen in focal facial spasms ${ }^{4}$ are all clinically distinct from the movements our patient had.

The movements are unlikely to be cortical (epileptic) seizures for several reasons. There was neither epileptiform activity in several EEGs nor evidence for a supratentorial lesion on CT scans. The pathology of the tumour makes a metastatic lesion unlikely and the laboratory data excluded an encephalitis.
The movements in our patient had several features of segmental rhythmic myoclonus, ${ }^{5,6}$ a type of nonepileptic myoclonus. ${ }^{7}$ The paroxysmal onset, waxing and waning character, and "march" of events are unusual for this condition and are more characteristic of 'Jacksonian' seizures. But segmental myoclonus may have some of the features of seizures ${ }^{5.8}$ and it may be impossible to clinically distinguish the two. ${ }^{5}$ Segmental myoclonus involves one or more muscle groups innervated from a limited region of brainstem or cerebellum. ${ }^{5.6}$ Tumoural infiltration of the brainstem is unlikely to have caused the involuntary movements because such infiltration by cerebellar astrocytoma is rare and our patient never had other clinical, radiological or electrophysiological evidence of brainstem involvement.

The involuntary movements in our case resemble those produced by cerebellar stimulation..${ }^{9.10}$ The focal onset and sequential "march" of movements can be explained by the presence of somatotopic representation in the cerebellum with distinct areas for the face, eyes and limbs. ${ }^{11}$ Cerebellar stimulation causes a similar "march" of clinical events in cats. ${ }^{12}$

The clinical and experimental evidence we have cited suggests that the cerebellum was primarily responsible for the involuntary movements in our patient. The marked improvement following tumour resection is compatible with this hypothesis. A cerebellar lesion should be considered in children with such movements.

\section{ACKNOWLEDGEMENTS}

We thank Drs. F.A. Booth. V. Chernick and N. Pillay for reviewing the manuscript. Dr. Pillay did the evoked potentials and orbicularis oculi reflex studies. The surgery was performed by Dr. D. Fewer.

\section{REFERENCES}

1. Auger RG. Hemifacial spasm: Clinical and electrophysiologic observations. Neurology (NY) 1979; 29: 1261-1272.

2. Espinosa RE, Lambert EH, Klass DW. Facial myokymia affecting the electroencephalogram. Mayo Clin Proc 1967; 42: 258-270.

3. Jankovic J, Patel SC. Blepharospasm associated with brainstem lesions. Neurology 1983; 33: 1237-1240.

4. Nudleman KL, Starr A. Focal facial spasm. Neurology 1983: 33: 1092-1095.

5. Swanson PD, Luttrell CN, Magladery JW. Myoclonus - A report of 67 cases and review of the literature. Medicine (Baltimore) 1962; 41: 339-356.

6. Rondot P, Bathien N, Toma S. Physiopathology of cerebellar movement. In: Massion J, Sasaki K, eds. Cerebro-cerebellar interactions. New York: Elsevier 1979: 203-230.

7. Hallett M. Myoclonus: relation to epilepsy. Epilepsia 1985; 26; Supplement (1): S67-77.

8. Bonduelle M. The myoclonias. In: Vinken PJ, Bruyn GW, eds. Handbook of Clinical Neurology, Vol. 6. New York: John Wiley and Sons, 1968: 761-781.

9. Nashold BS, Slaughter GD. Effects of stimulating or destroying the deep cerebellar regions in man. J Neurosurg 1969;31: 172-186.

10. Dauth GW, Defendini R, Gilman S, et al. Long-term surface stimulation of the cerebellum in the monkey. I. Light microscopic, electrophysiologic, and clinical observations. Surg Neurol 1977; 7: $377-384$.

11. Brodal A. Neurological anatomy. New York: Oxford University Press, 1981: 308-310.

12. Clark SL, Ward JW. Observations on the mechanism of experimental cerebellar seizures. J Neurophysiol 1952; 15: $221-234$. 